\title{
High Speed Hard Turning of AISI S1 (60WCrV8) Cold Work Tool Steel
}

\author{
Alaattin Kaçal ${ }^{1}$, Ferhat Yıldırım ${ }^{2}$ \\ 1* Department of Manufacturing Engineering, Faculty of Simav Technology, \\ Dumlupinar University, 43500, Simav - Kütahya / Turkey \\ e-mail: akacal@dumlupinar.edu.tr \\ ${ }^{2}$ Department of Machine Educational, Faculty of Simav Technical Education, \\ Dumlupinar University, 43500, Simav - Kütahya / Turkey
}

\begin{abstract}
This study deals with experimental results of high speed hard turning of hardened AISI S1 cold work tool steel with ceramic and CBN cutting tools. Ceramic and CBN tools performance were evaluated based on machining force, surface roughness and tool wear. Cutting speed, feed rate, depth of cut and tool types were determined as processes parameters. Evaluating tool wear type and wear mechanism by tool makers' microscope and SEM analysis. Analysis of variance (ANOVA) was used for observing that the most influencing machining parameters on the quality characteristics in terms of the statistically. CBN cutter exhibited a better performance than the ceramic cutter. For CBN and ceramic inserts, the increase in cutting speed increased the flank wear. After the turning of hardened workpiece, surfaces at grinding quality were obtained. It was predicted that, with the choice of appropriate cutting parameters, its hazardous effects of grinding operation on the environment and humans shall be decreased for such processes.
\end{abstract}

Keywords: Hard turning; cold work tool steel; cutting force; tool wear; surface roughness

\section{Introduction}

Especially, finishing of hardened steel parts using extra hard cutting tools offers manufacturers an alternative to grinding. Hard machining includes turning, milling and broaching. This machining method covers generally semi-finishing and finishing, operations [1]. The materials such as tool steels, die steels, bearing steel, alloys steels, case-hardened steels, white cast irons, and alloy cast irons are widely machining in hard machining operations.

In manufacturing industry, hard turning is a turning operation performed on hard or high strength alloy steels to reach high surface quality as grinding operations [2]. Lubricant can be eliminate, efficiency can be increasing and less energy than 
conventional methods by using hard turning operations. Manufacturing of the complex parts without the need for a second operation is another important characteristic of hard turning. Because of hard turning performed in dry machining condition, the harmful effect of cooling on environmentally can be eliminated. Due to very high hardness, high thermal hardness, wear resistance and very high strength level Ceramic, $\mathrm{CBN}$ and $\mathrm{PCD}$ cutting inserts are used in hard turning of hardened materials. [2, 3, 4, 5,6]. CBN tools exhibit low solubility, and satisfactory fracture toughness [6]. These cutting tools generate a better surface finish and lower flank wear on machining of hardened steel [7]. Ceramic tools can be used for the machining of hardened components in the manufacturing industry. Ceramic insert has high melting point, excellent hardness and good wear resistance. Ceramic inserts based on $\mathrm{Al}_{2} \mathrm{O}_{3}$ are used for machining the hardened materials [8]. Due to the high hardness and high strength of the work pieces, occur high temperatures on the cutting edge, diffusion tool and the chips interface, and wear on tool nose. It could be said that wear resistance and chemical stability are the most important properties of tool materials used for hard turning [6].

Although heavy catastrophic effect and reduction of tool lifetime, high speed machining (HSM) for hard turning has several advantages such as improvement of the surface roughness and increasing of productivity, achieve high removal rate [9, 10]. HSM has been developed as an eminent technology in rapid tooling and manufacturing applications. For the effective high speed manufacturing of materials which are poor machinability require advanced tooling such as coated carbides, ceramics and poly crystalline cubic boron nitride (PCBN) [11]. Sai [12] researched realization of a wear model in relation to time and to cutting speed. Sai obtained that it is possible to set optimal cutting speed to achieve the maximum tool life. Pawade et. al [13] presents an experimental investigation to assess the effect of machining process and cutting edge geometry related parameters on surface integrity in the high-speed turning of Inconel 718. Fang and $\mathrm{Wu}$ [14] investigated a comparative experimental study of high speed machining of two materials-titanium alloy $\mathrm{Ti}-6 \mathrm{Al}-4 \mathrm{~V}$ and Inconel 718 -have been performed. The results show that for both materials: as the cutting speed increases, the cutting force, the thrust force, and the result force all decrease; however, the force ratio increases. Thakur et. al [10] experimentally investigated on high-speed machining of Inconel 718 using cemented tungsten carbide insert tool. Chou et. al [15] investigated the performance and wear behavior of different cubic boron nitride (CBN) tools finish turning of hardened AISI 52100 steel. Experimental results revealed that low $\mathrm{CBN}$ content tools perform better than high $\mathrm{CBN}$ content. In spite of the low CBN content tools have subordinate mechanical properties. Additionally, Diniz and Oliveira [16] pointed out same results related to the effect of CBN content on machining of hardened steel.

Gaitonde et. al [17] investigated the relationships between the cutting conditions (cutting speed, feed rate, and machining time) on machinability aspects (machining force, power, specific cutting force, surface roughness, and tool wear). 
The machining force is highly sensitive to feed rate variations and the maximum tool wear occurs at a cutting speed of $150 \mathrm{~m} / \mathrm{min}$ for all values of feed rate. Lima et. al [18] experimentally studied the machinability of hardened steels at different hardness and cutting tool materials. AISI 4340 steel was conducted using of 42 and 48 HRC hardness. Firstly, coated carbide insert was used. Then, a PCBN insert was employed. The experimental tests on the hardened AISI D2 steel (58 HRC) were performed with a mixed alumina-cutting tool. According to the machining tests, obtained surface finish as good as that produced by cylindrical grinding. Davim and Figueira [19] studied using ceramic cutting inserts in surface finish operations on cold work tool steel AISI D2 heat treated to a hardness of 60 HRC. Experimental results revealed that with an appropriate cutting parameters choice is possible to obtain a surface roughness $(\mathrm{Ra}<0.8 \mu \mathrm{m})$. Cakir et. al [20] investigated the effects of cutting parameters on to the surface roughness using the mathematical model developed by using the data gathered from turning experiments. Higher feed rate leads to poor surface roughness, whereas cutting speed has an opposite effect and depth of cut has no significant effect. Işık [21] were performed a study to determine the machinability of tool steels. Results; Cutting speed is the most effective parameter on tool life, feed rate is the second and depth of cut is the least. Flank wear was the most encountered wear type. Increases in feed rate and cutting depth affect the surface quality negatively, while the increase of nose radius affects it positively. The different studies related to the machinability assessments on hard turning can be found in published scientific literature $[7,22,23,24,25,26]$.

In this study, machinability characteristics were investigated in hard turning of AISI S1 cold work tool steel widely used in manufacturing industry. Machining force, surface roughness, tool wear, evaluating of tool wear mechanism using Scanning Electron Microscope (SEM) and analysis of variance (ANOVA) were conducted in order to achieve the objective of the study.

\section{Experimental Set-up}

The AISI S1 (1.2550) cold work tool steel (hardened 60 HRC) which made by Dörrenberg Edelstahl in form of $100 \mathrm{~mm}$ diameter and $300 \mathrm{~mm}$ length was used as a work piece material. The chemical composition of work piece material is shown in Table 1. The AISI S1 has been using in cold shear knives, paper and wood cutting knives, cutting tools for plates up to $10 \mathrm{~mm}$, ejector pins and air hammers, because of the excellent wear resistance, high surface hardness and very good toughness, dimensionally stable, impact resistant and high hardening capacity [27]. 
Table 1

Chemical composition of AISI S1 experimental work piece (wt\%)

\begin{tabular}{|c|c|c|c|c|c|c|c|}
\hline $\mathrm{C}$ & $\mathrm{Si}$ & $\mathrm{Mn}$ & $\mathrm{P}$ & $\mathrm{S}$ & $\mathrm{Cr}$ & $\mathrm{W}$ & $\mathrm{V}$ \\
\hline 0.6 & 0.74 & 0.33 & 0.012 & 0.007 & 1.01 & 1.88 & 0.16 \\
\hline
\end{tabular}

The PVD TiN coated ceramic and CBN inserts which produced by SANDVIK Coromant were used in turning tests. The mixed alumina ceramic inserts designation code is SNGA 120408 S01525 6050 and low CBN content inserts code is SNGA 120408 S01030 A 7015. The inserts were clamped onto with a designation of DSBNR-2525-M12 (approach angle: $75^{\circ}$ ) tool holder. The geometry and properties of inserts is shown in Table 2.

The turning tests were performed (Figure 1-a) on JOHNFORD T35 CNC lathe having a maximum spindle speed of $4000 \mathrm{rpm}$ and a maximum power of $10 \mathrm{~kW}$ (Figure 1-b) in dry conditions. A KISTLER 9257B piezoelectric dynamometer and its equipments were used to measure three components of forces (cutting force $\left(F_{c}\right)$, feed force $\left(F_{f}\right)$ and passive force $\left(F_{p}\right)$ ) (Figure 1-c). Surface roughness $\left(R_{a}\right)$ was measured by using a Mahr Perthometer M1 with a cut-off length of 0.8 $\mathrm{mm}$. After each turning test, surface roughness was measured at intervals of $120^{\circ}$ on outer diameter surface (Figure 1-d).

Table 2

Properties of cutting inserts and tool holder

\begin{tabular}{|c|c|c|}
\hline Cutting Inserts & SNGA 120408 S01525 & SNGA 120408 S01030 \\
\hline & 5050 & \\
\hline Nose radius, $\mathrm{mm}$ & 0.8 & 0.8 \\
\hline Edge geometry & Chamfered and honed & Chamfered and honed \\
\hline Chamfer width, mm & 0.15 & 0.10 \\
\hline Chamfer angle & $25^{\circ}$ & $30^{\circ}$ \\
\hline Grade & 6050 (Sandvik Coromant) & 7015 (Sandvik Coromant) \\
\hline Tool holder & \multicolumn{2}{|c|}{ DSBNR-2525-M12 } \\
\hline Approach angle $(\mathrm{Kr})$ & \multicolumn{2}{|c|}{$75^{\circ}$} \\
\hline
\end{tabular}

The flank wear formed on cutting inserts was measured by Mitutoyo TM-500 tool makers' microscope with 40x magnification. Flank wear which occurring in constant chip removal volume was used in order to evaluating of the tool wear.

The machining force $\left(F_{m}\right)$ was determined by using the following equations:

$$
F_{m}=\sqrt{F_{c}^{2}+F_{f}^{2}+F_{p}^{2}}
$$


Machining parameters and their levels used in the machining tests are given in Table 3. Design of experiment was determined by full-factorial experimental design.

Table 3

Experimental machining parameters

\begin{tabular}{|c|c|c|c|}
\hline \multirow{2}{*}{ Machining Parameters } & \multicolumn{3}{|c|}{ Levels } \\
\cline { 2 - 4 } & 1 & 2 & 3 \\
\hline Cutting tool & Ceramic & CBN & ---- \\
\hline Cutting Speed, Vc $(\mathrm{m} / \mathrm{min})$ & 150 & 225 & 300 \\
\hline Feed rate, f $(\mathrm{mm} / \mathrm{rev})$ & 0.05 & 0.1 & 0.15 \\
\hline Depth of Cut $(\mathrm{mm})$ & 0.2 & 0.4 & 0.6 \\
\hline
\end{tabular}

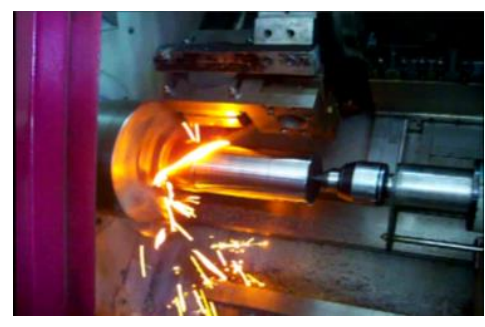

a) Performing of the tests

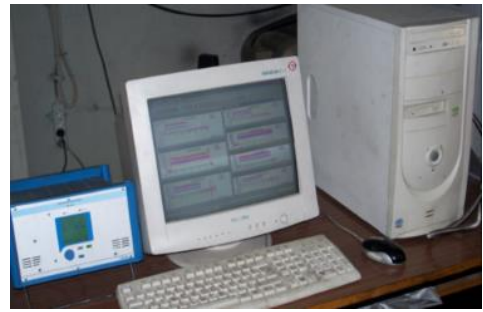

c) KISTLER 9257B dynamometer

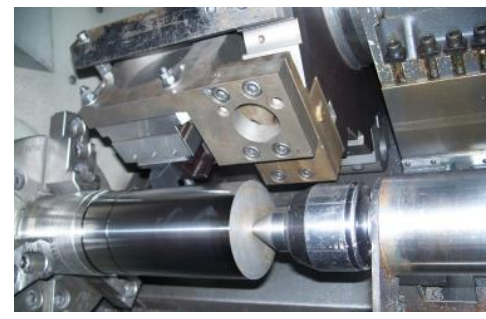

b) CNC lathe

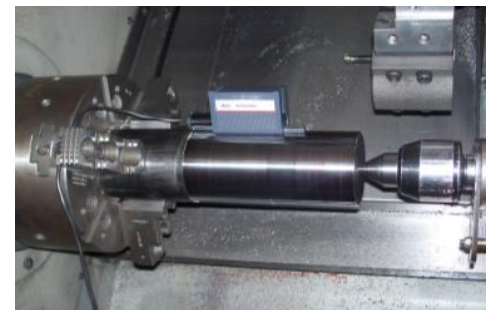

d) Surface roughness measurement

Figure 1

Experimental setup

\section{Results and Discussion}

Obtaining results after the tests were detailed under titles of surface roughness, cutting forces and tool wear respectively as follows. 


\subsection{Surface Roughness}

After each cutting experiment carried out according to the experiment parameters, the $R_{a}$ roughness values were measured over the machined surfaces. The graphs showing the correlations between the measured values and the cutting parameters are given in Figure 2.a and Figure 2.b The curves are placed based on cutting depths on the graphics.

As seen in Figure 2.a, in experiments carried out with ceramic cutting inserts, it is observed that the $\mathrm{R}_{\mathrm{a}}$ values increase in parallel with the increase in the feed rate values for all the three cutting speeds. With the raise of the feed rate value from $0.1 \mathrm{~mm} / \mathrm{rev}$. to $0.15 \mathrm{~mm} / \mathrm{rev}$., a significant increase is observed in the $R_{a}$ value. Furthermore, when evaluated with regards to cutting speeds, the roughness value obtained at the cutting speed of $150 \mathrm{~m} / \mathrm{min}$. is observed to be slightly higher in comparison with others. It was observed that the $\mathrm{R}_{\mathrm{a}}$ curves obtained at cutting speeds of 225 and $300 \mathrm{~m} / \mathrm{min}$. were close to each other. There, some improvement may be seen in roughness since the temperature increasing with the increasing cutting speed makes chip formation relatively easier. The effect of the increase in the cutting speed is low on $R_{a}$. However, it may cause a negative effect on $R_{a}$ after a point depending on the increase of the cutting speed and the tool wear. Especially, it is inevitable the fact that the machined material is hardened at a very high value shall worsen this situation.

When the graphs given in Figure 2.b and related to the experiments carried out with CBN cutting inserts are studied, significant increases in the $R_{a}$ value have been observed. Here, it is seen that feed rate has a significant effect on $R_{a}$. The increase in the cutting speed has displayed an improvement on $R_{a}$ similar to the ceramic inserts. Furthermore, with regards to cutting depths at low feed rate $(0.05$ $\mathrm{mm} / \mathrm{rev}$ ), there was change in the $\mathbf{R}_{\mathrm{a}}$ value; however, as the progress increased, an increase was displayed at high cutting depths. This situation may be explained through the negative effect that the combination of the increased chip crosssection with the hardness of the workpiece makes on the machined surfaces. When the $R_{a}$ values obtained under the same cutting conditions are compared with regards to cutting inserts, it may be said that the CBN cutting insert exhibits a better performance in relation to the ceramic cutting inserts. Considering that the ceramic cutting inserts are used in experiments with a harness above the recommended maximum piece hardness and that they are cheaper than the CBN cutting inserts, it may be considered that this improvement obtained with CBN cutting insert may be small. The best $R_{a}$ value was obtained under conditions at low feed rate and high cutting speeds for both cutting inserts. Lima et al. also suggested similar results [18]. 


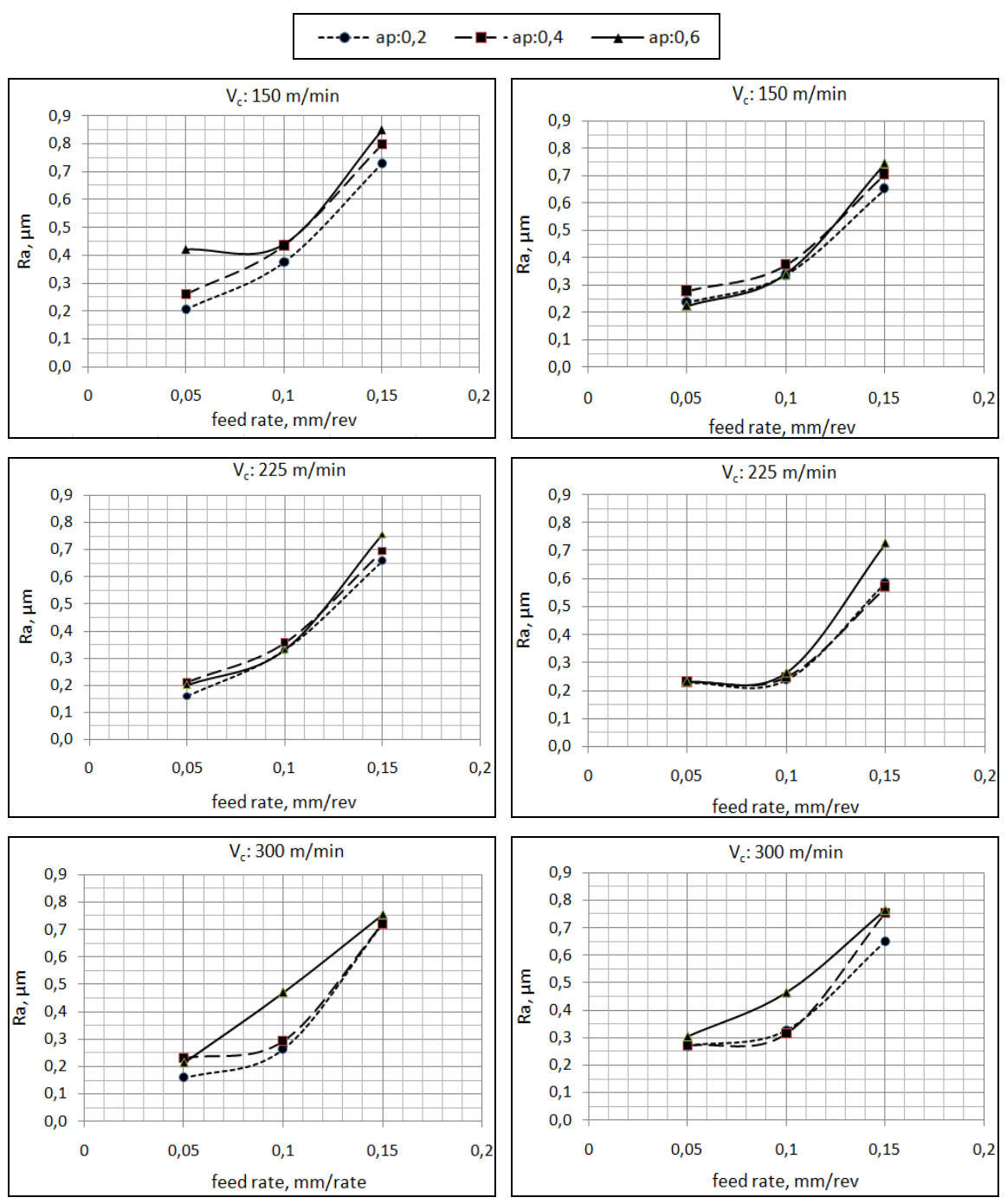

a)

b)

Figure 2

a) Variation at value of Ra depending on feed rate in hard turning of AISI S1 with ceramic inserts in different cutting speed

b) Variation at value of Ra depending on feed rate in hard turning of AISI S1 with CBN inserts in different cutting speed 


\subsection{Cutting Forces}

The machining force $\left(F_{m}\right)$ established as the evaluation criterion for the cutting forces was obtained via calculation (in accordance with Equation 1) from the force values measured in three directions via a dynamometer during the experiments.

In Figure 3.a, the change of the machining force depending on feed rate for the machining of AISI S1 steel at different cutting speeds with ceramic cutting inserts. When the graph is studied, it can be seen that the machining force increases in parallel with the increase in the feed rate. Since the increase of the feed rate value increases the chip cross-section, more force shall be required for chip formation. In this case, the cutting forces shall increase [28, 17]. Furthermore, similar increase rates were exhibited dependent on the increase of the depths of cut. Since the increases in the amounts of feed rate and depth of cut increase the chip crosssection, it is inevitable that this increases the force required for chip formation. When the results of the machining forces in the three graphs in Figure 3.a are evaluated, the machining force exhibited a trend to decrease in parallel with the increase in the cutting speed. It was observed that the trend to decrease is more distinctive at high feed rate and depths of cut (increasing chip cross-section). This situation may be related to the fact that the increase in the cutting speed improves the formation and removal of chips at the cutting region.

In Figure 3.b, the change of the machining force at different cutting speeds with CBN cutting inserts is shown depending on the feed rate. The increase in feed rate increased the machining force also in the cutting experiments carried out with CBN cutting tools. The increase in all the three graphs in the figure displayed parallelism to each other. With regards to depths of cut, it was observed that the machining force increases with increasing cutting depth. It is also observed that the increasing cutting speed decreases the processing speed in general. When the ceramic and CBN inserts are evaluated with regards to machining forces, it is seen that slightly lower machining forces are obtained in the cutting experiments carried out with CBN cuttings tools. The machining force, which is $127.399 \mathrm{~N}$ at a cutting speed of $300 \mathrm{~m} / \mathrm{min}$., at a feed rate of $0.05 \mathrm{~mm} / \mathrm{rev}$. and at a depth of cut of 0.2 for CBN cutting inserts, was $150.661 \mathrm{~N}$ with the same parameters for ceramic inserts. These values are the lowest values obtained for both inserts. The fact that CBN cutting inserts perform better on hardened steels has an influence on this situation. 


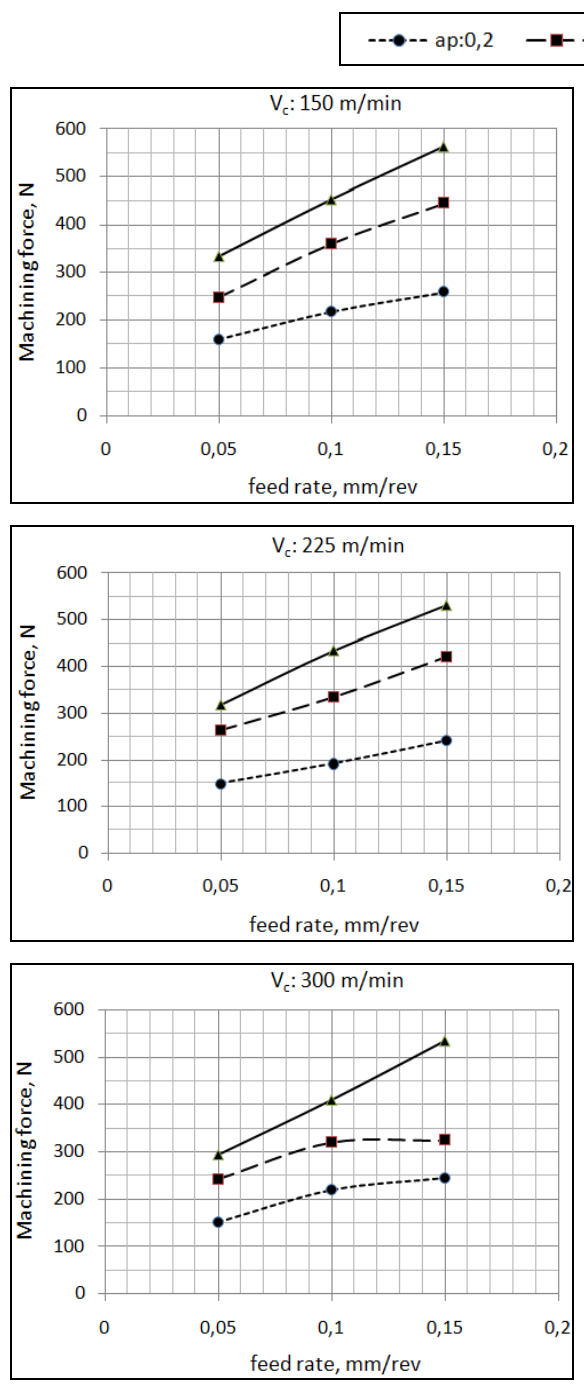

a)
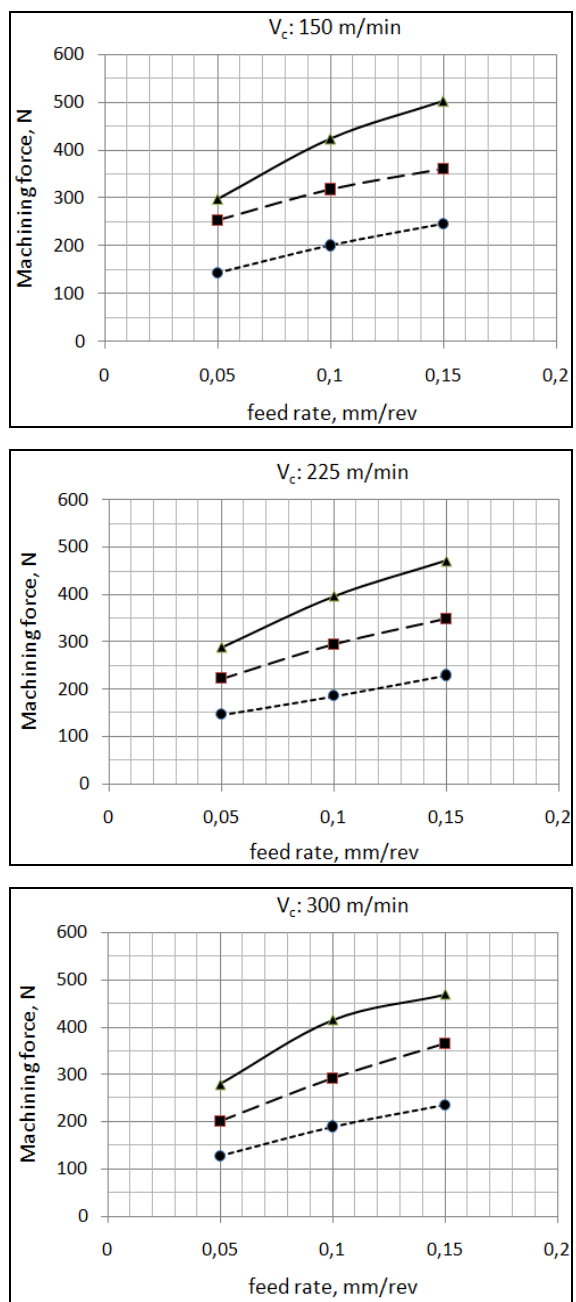

b)

Figure 3

a) Variation at machining force depending on feed rate in hard turning of AISI S1 with ceramic inserts in different cutting speed

b) Variation at machining force depending on feed rate in hard turning of AISI S1 with CBN inserts in different cutting speed 


\subsection{Tool Wear}

The flank wears were measured and evaluated as the result of the experiments carried out under fixed chip conditions for the wear criterion that is an important factor for the evaluation of the machining performance of hardened steels. Poulachon et. al [4] stated that the back-shift of the cutting edge as a result of wear has an important effect on the geometrical dimension of the work piece. Therefore, they suggested flank wear should be preferred with priority in the measurement and classification of tool wears [4]. The change of the flank wear on the cutting speed for AISI S1 steel with ceramic cutting inserts at different depths of cut is given in Figure 4.a. In all the three graphs, the increase in the cutting speed increased the flank wear. In general, in turning and milling operations, the factors affecting the toll wear are ordered, with regards to significance, as cutting speed, feed rate and depth of cut [29]. With the increasing of the cutting speed, the high-speed deformation and friction at the interface of the tool and the chip increases the temperature at the cutting region $[2,19,29,30]$. When turning hard pieces, the high hardness and strength of the work piece plays an important role in formation of high heat at the cutting side and between the tool and the chip [6]. It is observed that the increase amount of the flank wear is relatively low at depth of cut of 0.4 and $0.6 \mathrm{~mm}$, and distinctively high at the depth of cut of $0.2 \mathrm{~mm}$. The highest wear values are observed at a cutting speed of $300 \mathrm{~m} / \mathrm{min}$., a cutting depth of $0.2 \mathrm{~mm}$, and a feed rate of $0.015 \mathrm{~mm} / \mathrm{rev}$. Almost the same results are mentioned in other studies $[8,10,18]$.

In Figure 4.b, the change of flank wear vs. cutting speed is given for different depths of cutting with CBN cutting inserts. When the graphs given in the figures are studied, the flank wear values exhibit an increase with the increase in the depth of cut. Increasing cutting speeds increase the deformation on the tool at places where the cutting tool contacts the chips at the cutting region. Furthermore, looking at the graphs, it can be seen that the occurring tool wears are close to each other. Accordingly, it may be said that cutting depth does not have much more effect on the tool wear for the cutting experiments carried out with CBN cutter compared to ceramic cutters. 


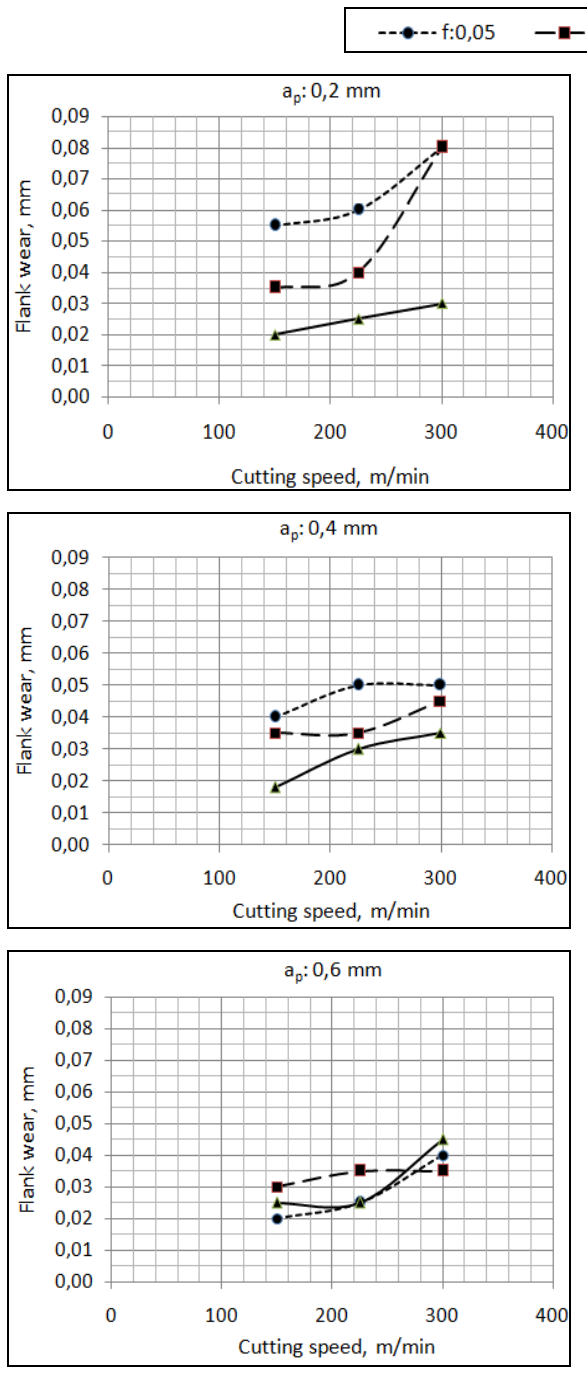

a)
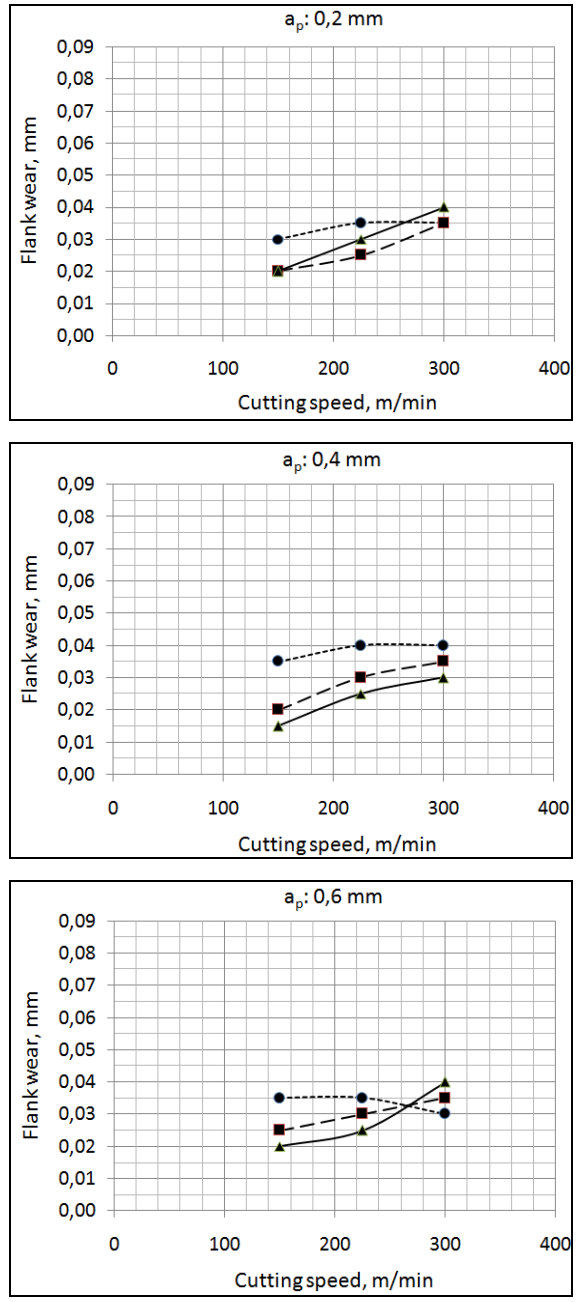

b)

Figure 4

a) Variation at flank wear depending on cutting speed in hard turning of AISI S1 with ceramic inserts in different depth of cut

b) Variation at flank wear depending on cutting speed in hard turning of AISI S1 with CBN inserts in different depth of cut

When ceramic and CBN cutting inserts are compared for the same cutting parameters, it is seen that the CBN cutting insert displays a better performance than ceramic cutter with regards to flank wear. 


\subsection{Wear Mechanism}

SEM images of the cutting inserts were taken and evaluated to assess more effectively the determination of wear mechanisms occurring in the cutting experiments and establishing wear types and consequent better evaluation of tool performance.

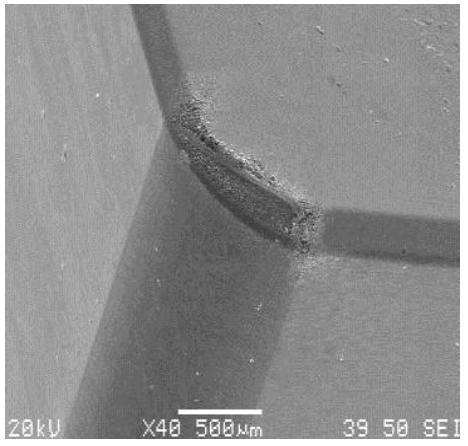

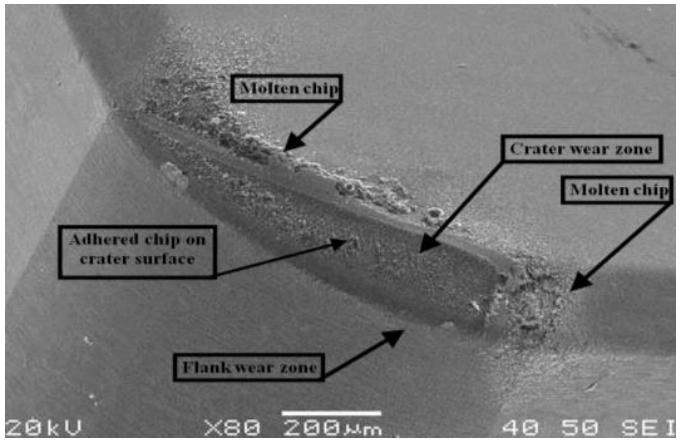

Figure 5

SEM photos of wears on ceramic insert ( $\left.V_{c}: 300 \mathrm{~m} / \mathrm{min} ., f: 0.15 \mathrm{~mm} / \mathrm{rev} . a_{p}: 0.4 \mathrm{~mm}\right)$

In Figure 5, the wear status of the ceramic insert with cutting parameters of $V_{c}$ : $300 \mathrm{~m} / \mathrm{min} ., f: 0.15 \mathrm{~mm} / \mathrm{rev}$, and $a_{p}: 0.4 \mathrm{~mm}$. In the figure, flank wear, crater wear, notch wear, and the molten chip and adhered chip on to the crater surface at the region where the chip surface and the insert diameter ends (where the contact of the chip with the cutting insert ends) can be seen clearly. In other studies on the turning of hard pieces, similar results are seen $[10,9]$. When the figure is studied, it seems possible that some indent wear shall occur after some more cutting on this area. Abrasion marks that are the result of the abrasive wear mechanism caused by the hard martensite particles inside the work piece were small [5]. The flank wear occurrence is quite small. When the crater wear at the chamfer area of the cutting insert is studied, it can be said that the crater size shall grow if the cutting process is continued. The main reason for crater wear is the sliding of the chip on the chip surface of the tool. The sliding movement abrades the rises and decreases the waviness of the surface [5]. Also, the presence of chip pieces adhering on the crater surface can be observed. These adhering pieces break during the ongoing cutting process and new pieces adhere to the emptied area. Abrasion gains acceleration after this point. However, the contact inside the crater at high cutting speeds is evaluated through the combination of very high temperature, great chip sliding speed and the adhering and accumulation of chips [9]. The adhering layers may also have a protective effect [9]. Looking at the wear area in general, it can be said that effects of slightly abrasive and intensely adhesive and diffusion wear mechanism are seen in the ceramic cutter. 


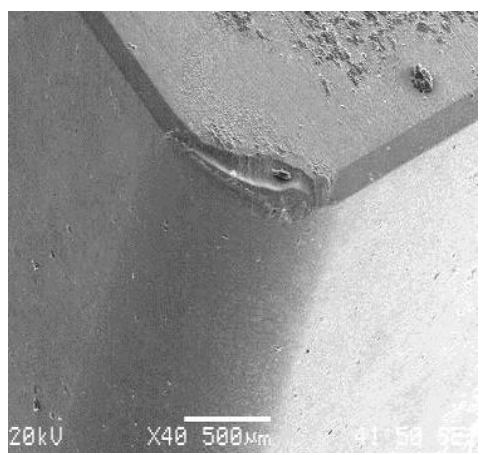

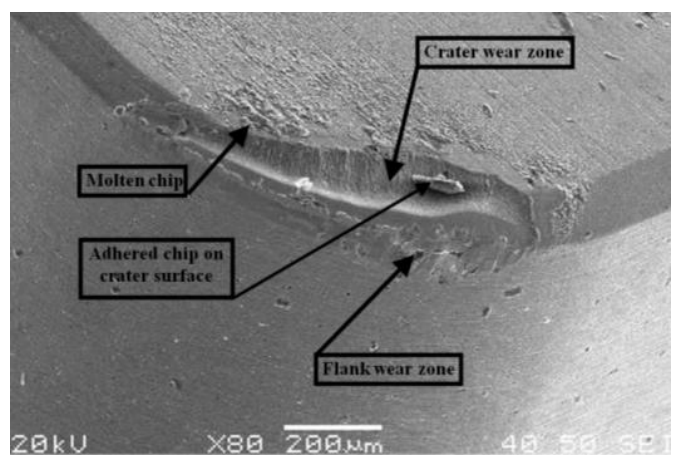

Figure 6

SEM photos of wears on CBN insert $V_{c}: 300 \mathrm{~m} / \mathrm{dak} ., f: 0.15 \mathrm{~mm} / \mathrm{dev} . a_{p}: 0.4 \mathrm{~mm}$ )

In Figure 6 is given the SEM image taken after the experiment carried out with CBN cutting insert at cutting conditions of $V_{c}: 300 \mathrm{~m} / \mathrm{min}$., $f: 0.15 \mathrm{~mm} / \mathrm{rev}$., and $a_{p}: 0.4 \mathrm{~mm}$. Flank wear, crater wear, newly developing notch wear, molten chip, and adhered chip on to the crater surface are observed. When the flank wear areas are studied, chips smeared under the effects of friction and pressure can be seen as well as abrasion wear marks formed in the cutting direction cutting. Crater wear is observed at high cutting speeds. The reason for this may be the fact that the carbides in the hardened work piece separate the bonds of the CBN binder and abrade the tool [2]. The main reason for crater wear is the sliding of the chip on the chip surface of the tool. The sliding movement abrades the rises and decreases the waviness of the surface [5]. At the small cutting area, the crater wear occurred at the chamfer zone of the cutting tool. The shape of the crater wear on the tool is related to the distribution of the pressure along the chip surface [9]. The crater wear occurring consequently can change the geometry of the cutting area suddenly $[5,9]$. While the fact that the cutting process is carried out on hardened pieces and at high cutting speed values is useful with regards to economy or quality, it also causes the formation of high temperatures at the cutting region. The increasing temperature increases the diffusion effect that facilitates crater formation. Furthermore, high cutting speeds give rise to serious tribological condition at the tool-chip interface, causes the tool coating to peel and the tool to act consequently as an uncoated tool [9]. When the figure is studied, the presence of chip can be seen that occurs at the region the contact of the chip with the tools ends and contact with air starts with a trend to develop. As a result, it can be said that effects of abrasive and intensely adhesive and diffusive wear mechanism are seen in the CBN cutter. 


\subsection{ANOVA Results of the AISI S1}

The effects of the cutting parameters on surface roughness, flank wear, and machining force were evaluated statistically using variance analysis. The obtained results were investigated under the titles of surface roughness, machining force and flank wear. ANOVA is a method most widely used and aims at determining significant parameters on response and measuring their effects [31]. The results of the variance analysis for $R_{a}$ values are given in Table 4 . As can be understood from the table, it is seen that, with regards to $\mathrm{P}$ values, the cutting speed, feed rate and cutting depth have a significant effect on $\mathrm{R}_{\mathrm{a}}$ and that the effect of the cutter type is insignificant. With the value of $\mathrm{F}=455.19$, it was seen that the change in the feed rate levels is the most effective parameter on $\mathrm{R}_{\mathrm{a}}$. According to the variance analysis results for the machining force $\left(F_{m}\right)$, it is observed that, at $95 \%$ confidence level, the effects of all the parameters on $F_{m}$ are significant. It was observed that the change in the cutting levels of the depth of cut with $F=298.36$ is the most effective parameter on $F_{m}$. Feed rate is the second significant parameter with the value of $141.31 \mathrm{~F}$.

Table 4

ANOVA results of surface roughness, machining force and flank wear

\begin{tabular}{|c|c|c|c|c|c|}
\hline \multicolumn{6}{|c|}{ Surface roughness } \\
\hline Source & DoF & SS & MS & $\mathrm{F}$ & $\mathrm{P}$ \\
\hline Tool type & 1 & 0.00904 & 0.00904 & 3.71 & 0.060 \\
\hline Cutting speed & 2 & 0.05597 & 0.02798 & 11.49 & 0.000 \\
\hline Feed rate & 2 & 2.21635 & 1.10818 & 455.19 & 0.000 \\
\hline Depth of cut & 2 & 0.05344 & 0.02672 & 10.98 & 0.000 \\
\hline Residual error & 46 & 0,11199 & 0.00243 & & \\
\hline Total & 53 & 2.44678 & & & \\
\hline \multicolumn{6}{|c|}{ Machining force } \\
\hline Tool type & 1 & 10222 & 10222 & 14.51 & 0.000 \\
\hline Cutting speed & 2 & 6675 & 3338 & 4.74 & 0.013 \\
\hline Feed rate & 2 & 1999140 & 99570 & 141.31 & 0.000 \\
\hline Depth of cut & 2 & 420457 & 210229 & 298.36 & 0.000 \\
\hline Residual error & 46 & 32412 & 705 & & \\
\hline Total & 53 & 668906 & & & \\
\hline \multicolumn{6}{|c|}{ Flank wear } \\
\hline Tool type & 1 & 0.0038845 & 0.0038845 & 10.04 & 0.003 \\
\hline Cutting speed & 2 & 0.0059364 & 0.0029682 & 7.67 & 0.001 \\
\hline Feed rate & 2 & 0.0021681 & 0.0010841 & 2.80 & 0.071 \\
\hline Depth of cut & 2 & 0.0044481 & 0.0022241 & 5.75 & 0.006 \\
\hline Residual error & 46 & 0.0178008 & 0.0003870 & & \\
\hline Total & 53 & 0.0342380 & & & \\
\hline
\end{tabular}


When the variance analysis results of flank wear values is studied, it is seen that the changes in tool type, cutting speed and depth of cut have a significant effect on flank wear an that the effect of progress at $95 \%$ confidence level is insignificant. It was observed that tool type is the most effective parameter with $\mathrm{F}=10.04$.

When the experimental findings are studied in general, the smallest ideal $R_{a}$ value was found with $\mathrm{CBN}$ cutting insert at the cutting conditions of $\mathrm{V}_{\mathrm{c}}=225 \mathrm{~m} / \mathrm{min}$., $\mathrm{f}=$ $0.05 \mathrm{~mm} / \mathrm{rev}$. and $\mathrm{a}_{\mathrm{p}}=0.2 \mathrm{~mm}$; the most ideal result at cutting conditions of $\mathrm{V}_{\mathrm{c}}=$ $300 \mathrm{~m} / \mathrm{min}, \mathrm{f}=0.05 \mathrm{~mm} / \mathrm{rev}$. and $\mathrm{a}_{\mathrm{p}}=0.2 \mathrm{~mm}$; the lowest flank wear with CBN cutting insert at cutting conditions of $\mathrm{V}_{c}=150 \mathrm{~m} / \mathrm{min}$., $\mathrm{f}=0.15 \mathrm{~mm} / \mathrm{rev}$. and $\mathrm{a}_{\mathrm{p}}=0.6$ $\mathrm{mm}$. With regards to all the three environment criteria, CBN tool displayed a better performance. It is seen that the greatest problem encountered in turning of hard pieces is the rapid wear of the tool in a short time. Therefore, when determining the ideal cutting conditions, cutting speed may be increases to a degree. Since the first expectations in turning of hard pieces are a good surface smoothness and also enabling the longest lifetime for the tool, this correlation should be kept at an optimum level when determining the cutting parameters.

\section{Conclusions}

The experiments of AISI S1 material are carried out satisfactorily and the results obtained from the experiments were evaluated graphically and using ANOVA, which is one of the statistical techniques.

During the high-speed finishing turning of hardened AISI S1 material, the best results with regards to surface roughness were obtained with CBN cutters. The increase in the feed rate value increased the roughness for both cutters. With regards to turning operations, a roughness value of approximately $0.2 \mu \mathrm{m}$ was obtained, which is very good.

For both cutters, while the machining force increased depending on the increase of the feed rate and cutting depth, it decreased depending on the increase of the cutting speed With regards to machining force, CBN cutting inserts exhibited better performance than ceramic inserts.

For CBN and ceramic inserts, the increase in cutting speed increased the flank wear. With regards to flank wear, CBN cutter exhibited a better performance than the ceramic cutter for the same cutting parameters.

According to the study of the SEM images, it was determined that effects of slightly abrasive and intensely adhesive and diffusive wear mechanism are seen in the ceramic cutter. For CBN cutting inserts, abrasive and intensely adhesive and diffusive wear mechanisms are seen for the CBN cutters.

According to the ANOVA results, it was seen the change in progress levels is the most effective parameter on surface roughness $\left(R_{a}\right)$ statistically. It was shown that the change of tool types did not lead to much change. 
It was observed that the change in the cutting levels of the cutting depth with $\mathrm{F}=$ 298.36 is the most effective parameter on $F_{m}$.

According to the ANOVA results, it was determined that the effects of the changes in tool type and the values of the cutting speed and the depth of cut are significant and that the effect of feed rate is insignificant. It was seen that the tool type is the most effective parameter with the value of $\mathrm{F}=10.04$.

After the turning of both hardened materials investigated within the scope of the study, surfaces at grinding quality were obtained. It was predicted that, with the choice of appropriate cutting parameters, grinding operation and its hazardous effects on the environment and humans shall be decreased for such processes.

\section{Acknowledgement}

The authors would like to thank the Dumlupinar University, Department of Scientific Research Projects for funding this research (Project code: 2010/5). Besides, the authors thank the Gazi University Faculty of Technology Manufacturing Engineering Department and Dr. Yakup Turgut because of contribution in performing of machining tests.

\section{References}

[1] Grzesik W., Influence of Tool Wear on Surface Roughness in Hard Turning Using Differently Shaped Ceramic Tolls, Wear, 265, 2008, 327-335

[2] Poulachon G., Moisan A. and Jawahir I. S., Tool-Wear Mechanisms in Hard Turning with Polycrystalline Cubic Boron Nitride Tools, Wear, 250, 2001, 576-586

[3] Chou Y. K., Song H., Tool Node Radius Effects on Finish Hard Turning, J. Mater. Process. Technology, 148, 2004, 259-268

[4] Poulachon G., Bandyopadhyay B. P., Jawahir I. S., Pheulpin S. and Seguin E., Wear behavior of CBN Tools while Turning Various Hardened Steels, Wear, 256, 2004, 302-310

[5] More A. S., Jiang W., Brown W. D. and Malshe A. P., Tool Wear and Machining Performance of CBN-TiN-coated Carbide Inserts and PCBN Compact Inserts in Turning AISI 4340-hardened Steel, J. Mater. Process. Technology, 180, 2006, 253-262

[6] Derakhshan E. D. Akbari A. A., Experimental Investigation on the Effect of Workpiece Hardness and Cutting Speed on Surface Roughness in Hard Turning with CBN Tools, Proceeding of The World Congress on Engineering, 2009, Vol:2, London

[7] Tamizharasan T., Selvaraj T. and Noorul Haq A., Analysis of Tool Wear and Surface Finish in Hard Turning, Int. J. Adv. Manuf. Technol., 2006, 28:671-679 
[8] Horng J. T., Liu N. M. and Chiang K. T., Investigating the Machinability Evaluation of Hadfield Steel in the Hard Turning with $\mathrm{Al}_{2} \mathrm{O}_{3} / \mathrm{TiC}$ Mixed Ceramic Tool Based an the Response Surface Methodology, J. Mater. Process. Technology, 208, 2008, 532-541

[9] Mahfoudi F., List G., Molinari A., Moufki A. and Boulanour L., High Speed Turning for Hard Material with PCBN Inserts: Tool Wear Analysis, Int. J. Machining and Machinability of Materials, Vol:3 Nos. 1/2 2008

[10] Thakur D. G., Ramamoorthy B. and Vijayaraghavan L., Machinability Investigation of Inconel 718 in High Speed Turning, Int. J. Adv. Manuf. Technol., 2009, 45:421-429

[11] Umer U., Butt S. I., Askari S. J., Danish S. N. and Xie L., Comparative Analyses for Different Modeling Methods in High Speed Turning Operations for Hardened Steel, J. Mech. Engng., 54, 2008, 12, 850-854

[12] Sai W. B., An Investigation of Tool Wear in High Speed Turning of AISI 4340 Steel, Int. J. Adv. Manuf. Technology, 2005, 26:330-334

[13] Pawade R. S., Joshi S. S. and Brahmankar P. K., Effect of Machining Parameters and Cutting Edge Geometry on Surface Integrity of High Sped Turned Inconel 718, International Journal of Machine Tools and Manufacture, 48, 2008, 15-28

[14] Fang W., Wu Q., A Comparative Study of the Cutting Forces in High Speed Machining of Ti-6Al-4V and Inconel 718 with a Round Cutting Edge Tool, J. Mater. Process. Technology, 209, 2009, 4385-4389

[15] Chou Y. K., Evans C. J. and Barash M. M., Experimental Investigation on CBN Turning of Hardened AISI 52100 Steel, J. Mater. Process. Technology, 124, 2002, 274-283

[16] Diniz A. E., Oliveira A. J., Hard Turning of Interrupted Surfaces Using CBN Tools, J. Mater. Process. Technology, 195, 2008, 275-281

[17] Gaitonde V. N., Karnık S. R., Figueira L. and Davim P., Analysis of Machinability During Hard Turning of Cold Work Tool Steel (Type:AISI D2), Materials And Manufacturing Processes, 24:2009, 1373-1382

[18] Lima J. G., Avila R. F., Abrao A. M., Faustino M. and Davim J. P., Hard Turning: AISI 4340 High Strength Low Alloy Steel and AISI D2 Cold Work Tool Steel, J. Mater. Process. Technology, 169, 2005, 388-395

[19] Davim J. P., Figueira L., Machinability Evaluation in Hard Turning of Cold Work Tool Steel (D2) with Ceramic Tools Using Statistical Techniques, Mater. Des, 28, 2007, 1186-1191

[20] Çakır M. C., Ensarioğlu C. and Demirayak I., Mathematical Modeling of Surface Roughness for Evaluating the Effects of Cutting Parameters and Coating and Coating Material, J. Mater. Process. Technology, 209, 2009, 102-109 
[21] Işı1k Y., Investigating the Machinability of Tool Steels in Turning Operations, Materials and Design, 28, 2007, 1417-1424

[22] Huang Y., Liang S. Y., Force Modeling in Shallow Cuts with Large Negative Rake Angle and Large Node Radius Tools-Application to Hard Turning, Int. J. Adv. Manuf. Technology, 2003, 22:626-632

[23] Zhou J. M., Walter H., Andersson M. and Stahl J. E., Effect of Chamfer Angle on Wear of PCBN Cutting Tool., International Journal of Machine Tools and Manufacture, 43, 2003, 301-305

[24] Kundrak J., Karpuschewski B., Gyani K. and Bana V., Accuracy of Hard Turning, J. Mater. Process. Technol., 202, 2008, 328-338

[25] Singh D., Rao P. V., Improvement in Surface Quality with Solid Lubrication in Hard Turning, Proceeding of The World Congress on Engineering, 2008, Vol:3, London

[26] Qian L., Hossan M. R., Effect on Cutting Force in Turning Hardened Tool Steels with Cubic Boron Nitride Inserts, J. Mater. Process. Technology, 191, 2007, 274-278

[27] http://www.doerrenberg.de/

[28] Fnides B., Aouici H. and Yallese M. A., Cutting Forces and Surfaces Roughness in Hard Turning of Hot Work Steel X38CrMoV5-1 Using Mixed Ceramic, Mechanika, 2008, Nr:2, 70

[29] Davim J. P., Maranhao C., Faria P., Abrao A., Rubio J. C. and Silva L.R., Precision Radial Turning of AISI D2 Steel, Int. J. Adv. Manuf. Technol., 2009, 42:842-849

[30] Sahin Y., Comparison of Tool Life between Ceramic and Cubic Boron Nitride (CBN) Cutting Tool when Machining Hardened Steels, J. Mater. Process. Technology, 209, 2009, 3478-3489

[31] Kacal, A and Gulesin, M., Determination of Optimal Cutting Conditions in Finish Turning of Austempered Ductile Iron Using Taguchi Design Method. Journal of Scientific \& Industrial Research, 2011, 70, 278-283 